\title{
1/||||||||||||||||||||||||||||||||||||||||||||||||||||||||||||||||'.
}

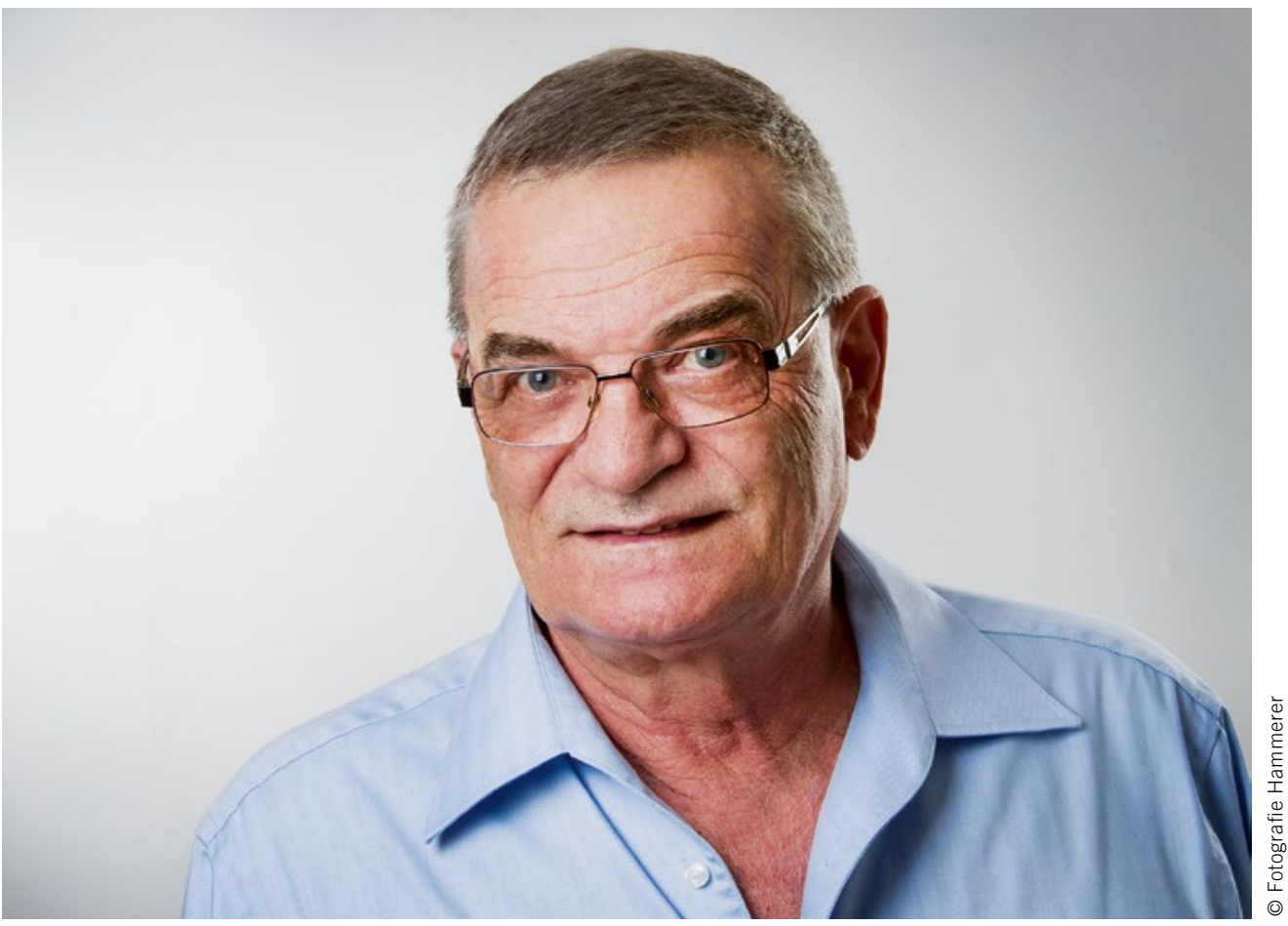

Holger Großmann

Springer-Vieweg Technical Author, Leader of Conferences and

Seminars, formerly at Audi AG

\section{Comparing the Refrigerant R1234yf and $\mathrm{CO}_{2}$}

Thermodynamically, the new refrigerant R1234yf behaves similarly to the current product R134a. However, its global warming potential or GWP is only 4, as opposed to 1430 (GWP figures from 2013). The refrigerant R744 (carbon dioxide or $\mathrm{CO}_{2}$ ) has been assigned a GWP value of 1 and functions as the reference gas. EU Commission Directive 2006/40/EC specifies that from 1 January 2017 only refrigerants with a GWP lower than 150 can be used in the air conditioning systems of new vehicles. R1234yf and R744 meet the requirements of the directive, but R1234yf contains hydrogen fluoride, which can form hazardous hydrofluoric acid if a fire breaks out in the car. The only modification required for the use of R1234yf is a new expansion valve. This increases the mass flow rate of the refrigerant in order to compensate for the lower specific heat of evaporation.

Systems designed for use with R744 have pressures up to ten times higher than those intended for R1234yf. In summer, the peak pressure is around 100 bar, which is above the critical pressure level (supercritical process). This makes controlling the system more difficult, but not problematic. The coefficient of performance or COP is the same in moderate climate conditions, but slightly poorer in hot, moist climate zones. The system can be designed to compensate for this, as the components are smaller because of the higher volumetric cooling capacity of R744.

In electric cars, using electricity to heat the passenger compartment in winter can reduce the range by up to $50 \%$. Heat pumps can compensate for this problem to a certain extent, but in the case of R1234yf heat pumps this is only possible at ambient temperatures no lower than $-5{ }^{\circ} \mathrm{C}$. If the temperature falls below this level, additional electric heating is needed. By contrast, R744 heat pumps supply more heat at temperatures below $-5{ }^{\circ} \mathrm{C}$ and have no leaks of the kind that develop in other systems as a result of negative pressure conditions. This makes R744 the preferred solution. In all heat pumps that use ambient air as a heat source, the heat exchanger in the front of the car can ice up because of spray and slush. This problem still needs to be resolved.

Air conditioning systems cool and dehumidify the air. The condensate that forms as a result of this process is released externally. However, around 0.31 of water remains in the evaporators of existing air conditioning systems after operation. Biological processes in the water can cause unpleasant odours to develop. The remaining water can also cause sudden condensation on the car's windows. These issues can be avoided by using R744 systems, which will have a completely new evaporator design.

At the $14^{\text {th }}$ Karlsruhe Air Conditioning Symposium organised by TWK GmbH on 2 June 2016, it emerged that there are no technical obstacles to prevent R744 from being used in automotive air conditioning systems. In my view, R1234yf can only be a temporary solution, while R744 has a promising future, particularly in electric cars. 